\title{
政府投资项目绩效审计 基于信息摘值法的案例研究
}

\author{
油翠英 \\ 扬州市固定资产投资审核中心，江苏扬州 225000
}

\begin{abstract}
[摘要] 绩效审计是政府投资项目审计的重要环节, 而审计方法的选择对项目绩效评价尤为重要。文章选用信息摘值法对绩效 审计评价指标权数进行客观赋值，最终计算出政府投资项目运行绩效情况，有效反映了政府投资项目作为复杂开放系统评价 指标的重要性和运行绩效的变化规律。并根据所建模型及公式进行了案例分析, 验证了模型的有效性和实用性, 实现了对政 府投资项目运行绩效的有效评价。为改进审计工作思路和方法，创新政府投资项目审计监督模式提供参考。
\end{abstract}

[关键词]政府投资项目; 政策执行; 绩效审计; 信息摘值法

DOI：10.33142/aem.v2i1.1440 中图分类号：D630.1 文献标识码：A

\section{Government Investment Project Performance Audit _Based on Study of Information Entropy Method}

YOU Cuiying

Yangzhou Fixed Assets Investment Audit Center, Yangzhou, Jiangsu, 225000, China

\begin{abstract}
Performance audit is an important part of government investment project audit and choice of audit method is particularly important for project performance evaluation. This paper selects information entropy method to evaluate weight of performance audit evaluation index objectively and finally calculates operation performance of government investment projects, which effectively reflects importance of government investment projects as evaluation index of complex open system and change law of operation performance. According to established model and formula, a case study is carried out to verify effectiveness and practicability of model and achieve an effective evaluation of operation performance of government investment projects. It provides a reference for improving the ideas and methods of audit work and innovating the audit supervision mode of government investment projects.
\end{abstract}

Keywords: government investment projects; policy implementation; performance audit; information entropy method

\section{引言}

政府投资项目的绩效审计即是对政策执行、项目建设和运营结果的审计和评价。最高审计机关国际组织 (INTDSAI) 对绩效审计的定义为: 绩效审计是经济性、效率性和效果性（简称 3E）审计; 刘家义审计长对绩效审计的定义为: 绩 效审计是对政府履行公共责任, 配置、管理、利用经济与社会资源的合理性、有效性、科学性进行审查、分析、考量 和评价 ${ }^{[1]}$ 。综合上述两种观点和表述, 政府投资项目的绩效审计可定义为: 政府投资项目的绩效审计是指对政府投资项 目所使用和管理的财政性资金经济型、效率性、效果性和合理性等方面进行的监督检查和评价行为。近年来，全国各 地审计部门在政府投资项目绩效审计方面都作出了大量的尝试和探索，例如广州市审计局对中山大道快速公交 (BRT) 试 验线工程项目和大中修工程 (广州大道黄埔夏园) 项目建设和运营情况绩效审计, 深圳市审计局对产业聚集地建设和运 营情况绩效审计等。然而绩效审计因相应制度不健全、评价指标标准贫乏、审计力量不足等诸多原因在许多地方开展 不积极, 导致目前绩效审计呈现出 “百家争鸣” 局面, 并未形成统一且可行性高的指标体系和评价方法, 所以亟须设 计出能够符合政府投资项目绩效审计要求的评价指标体系和方法。此外, 国务院发布的《国务院关于加强审计工作的 意见》中指出要把绩效理念贯穿审计工作始终，审计署发布的《审计署关于进一步完善和规范投资审计工作的意见》 也指出为进一步完善和规范投资审计工作要坚持突出重点, 切实提高投资审计工作的质量和效果。如何实施绩效审计 是审计工作者需要面对的考验和问题。结合笔者所从事的政府投资项目审计工作，本文在政府投资项目绩效审计方面 尝试进行分析和研究。

\section{1 政府投资项目绩效审计评价指标体系的构建}

\section{1 指标体系的构建}

我国政府投资项目的绩效审计长期以来缺乏统一评价标准, 且已实施的绩效审计评价指标也大多集中在财务评价 方面。而政府投资项目的特点在指标体系中并未得以体现，如建设周期长、所需资金量大、政府起主导作用、项目具 有相对非竞争性和公共性等。因此, 结合绩效审计的定义, 政府投资项目绩效审计理想的评价指标体系构建应满足以 下需求：(1)能够充分反应政府投资项目的特点; (2)能够充分体现 “3E” 审计; (3)能够满足系统性和可操作性相结合的 原则。国家发展改革委和建设部联合发布的《建设项目经济评价方法与参数》(第三版) 就建设项目的财务分析、费用 
效果分析、经济影响分析等方面提出了诸多评价方法和指标, 并且在其指导下, 交通、水利、铁路、电力、邮电通讯、 石油化工等行业主管部门均颁布实施了本行业建设项目经济评价的方法与参数。国资委于 2005 年组织编制的《中央企 业固定资产投资项目后评价工作指南》中，充分结合了固定资产投资项目的特点，设计了包括工程技术、采购与支付 等能够充分体现投资项目特点的 14 项评价指标。财政部在 2004 年发布的《关于开展中央政府投资项目预算绩效评价 工作的指导意见》中, 建立了绩效评价的 22 个一般性指标, 形成了绩效评价指标体系的整体框架 ${ }^{[2]}$ 。经过多年实践表 明, 上述三种指标体系具有现实指导意义。本文在上述三点基础上, 结合政府投资项目特点做适当调整, 构建了一套 政府投资项目绩效审计评价指标体系，详见表 1 。

表 1 政府投资项目绩效审计评价指标体系

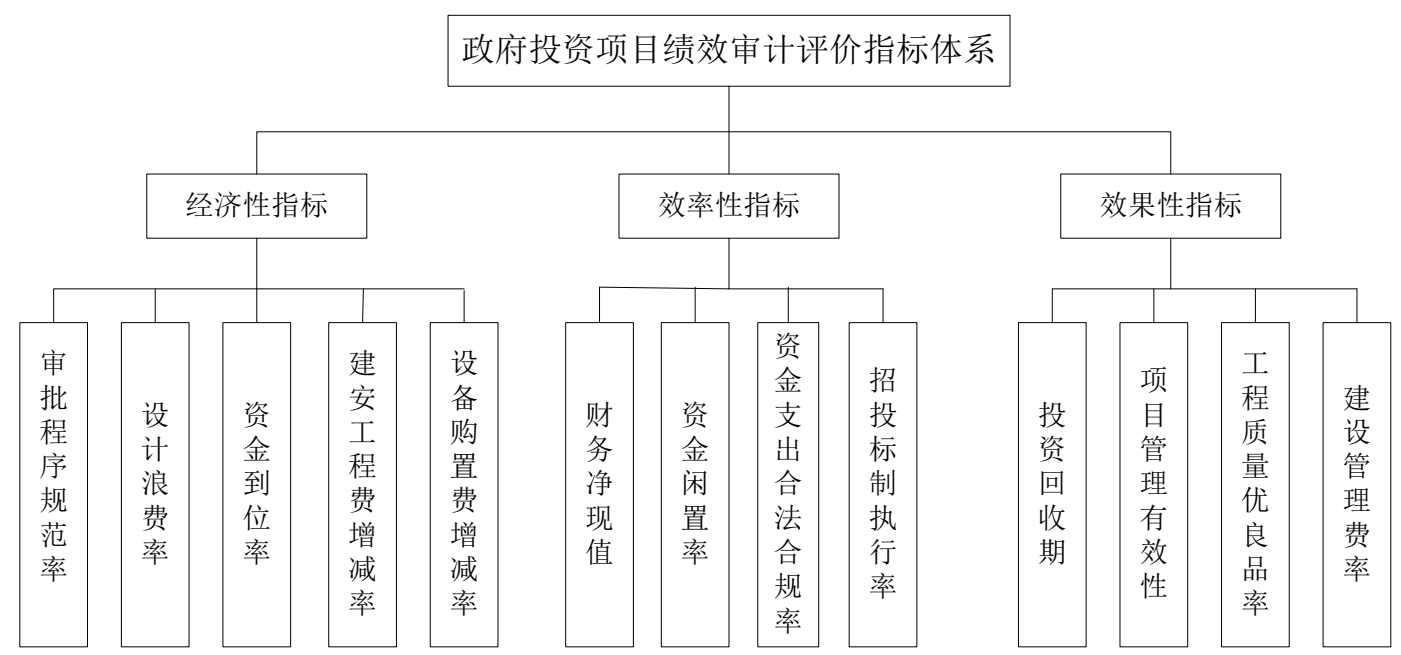

\section{2 定性指标因素的处理}

在评价指标体系中，只有 “项目管理有效性” 属于定性指标，不易通过具体的数值对其进行评价，所以要运用一 定的方法对其进行定量化处理。专家打分法是评价指标数量化方法的一种, 针对以上指标体系中定性因素的处理拟采 用专家打分法, 利用专家丰富的经验和感觉给出待估对象指标的分值, 最终得出综合评分, 从而能够在专家丰富经验 的基础上, 将待估对象的定性指标因素合理量化 ${ }^{[3]}$ 。

专家打分法的评估过程如下: 首先邀请专家按给定的评估指标因素, 对待估对象进行独立打分, 然后再按形同的 过程和规则对备选方案进行评估。本文一共选取了 8 名专家对政府投资项目的 “信项目管理有效性” 进行评价打分, 评分专家要根据自己的专业和主观感觉对其进行考察, 并按一定的记分制来打分, 再将每个得分相加, 就得到了这个 指标的总得分 ${ }^{[4]}$ 。本文专家将对此指标因素分别以好、较好、一般、差 4 种形式进行打分, 其中, 好记 4 分, 较好记 3 分, 一般记 2 分, 差记 1 分。

\section{2 基于信息熵值法的综合评价模型}

\section{1 信息摘理论的基本概念}

熵（Entropy）指的是体系的混乱程度。对于绩效评价，指标所反映的信息程度越高，信息熵就越小，该指标提供 的信息量就越大，在综合评价中所起的作用就越大。反之，指标的信息熵越大，该指标提供的信息量就越小，在评价 中所起的作用就越小。政府投资项目的绩效审计评价是一个需要采用多指标综合的评价问题, 即把多个描述被评价对 象中经济、效率和效果的量纲不同的一组统计指标, 转化成为无量纲的相对评价值, 并综合这些评价值以得出该政府 投资项目政策执行情况绩效的一个总体评价。利用熵值法对各个指标的权系数进行客观赋值, 可有效反映政府投资项 目作为复杂开放系统的变化规律, 这与物理学意义上的耗散结构系统类似 ${ }^{[5]}$ 。所以运用信息熵值法能够比较客观、真实 评价政府投资项目政策执行情况的绩效。

\section{2 基于信息摘值法的绩效评价步骤}

(1) 指标标准化

设政府投资项目统计数据为 $n$ 个样本, 绩效评价体系指标有 $m$ 个, $r_{i j}(i=1,2, \cdots, n, j=1,2, \cdots, m)$ 为第 $i$ 个样本在 第 $\mathrm{j}$ 个指标上的值。将各个评价指标进行标准化处理, 处理成为统一数量级的、越大越好的标准数据。

正向指标:

负向指标:

$$
r_{i j}{ }^{\prime}=r_{i j} / r_{j \max }
$$


（2）计算各指标的比重

$$
r_{i j}{ }^{\prime}=r_{j \min } / r_{i j}
$$

$$
f_{i j}=\frac{r_{i j}^{\prime}}{\sum_{i=1}^{n} r_{i j}{ }^{\prime}}
$$

（3）计算第 $\mathrm{j}$ 项指标的熵值

$$
H_{j}=-k \sum_{i=1}^{n} f_{i j} \ln f_{i j}
$$

其中, $k>0, \quad{ }_{j} \geq 0, k=\frac{1}{\ln n}$ 。

（4）计算第 $\mathrm{j}$ 项指标的信息效用值

对于第 $\mathrm{j}$ 项指标, 各样本指标值的信息效用值越大, 对样本评价作用越大, 熵值就越小, 定义信用效用值为:

$$
g_{j}=1-H_{j}
$$

（5）定义权重

$$
w_{j}=\frac{g_{j}}{\sum_{j=1}^{m} g_{j}}
$$

（6）计算样本绩效评价值

$$
V_{i}=\sum_{j=1}^{m} w_{j} f_{i j}
$$

$V_{i}$ 为第 $i$ 个样本的绩效评价值。

\section{3 案例分析}

为使样本具有可比较性，现抽取同一时间施工、项目性质类似的 3 个政府投资项目为绩效审计对象（以下简称 A、 B、C）为案例研究对象，来验证信息摘值法进行政府投资项目绩效审计的可行性。

首先根据选取的 8 名专家相互独立地对这三个项目 “项目管理有效性” 的评价，进行打分汇总及计算结果，如表 2 所示:

表 2 项目管理有效性评价

\begin{tabular}{c|c|c|c}
\hline \multirow{2}{*}{ 专家 } & \multicolumn{3}{|c}{ 评价项目名称 } \\
\cline { 2 - 4 } & $\mathrm{A}$ & $\mathrm{B}$ & $\mathrm{C}$ \\
\hline \multirow{2}{*}{$\mathrm{I}$} & 差 & 较好 & 一般 \\
\hline II & 一般 & 一般 & 较好 \\
\hline III & 较好 & 一般 & 较好 \\
\hline IV & 一般 & 较好 & 一般 \\
\hline V & 一般 & 差 & 较好 \\
\hline VI & 一般 & 好 & 较好 \\
\hline VII & 差 & 较好 & 一般 \\
\hline VIII & 较好 & 较好 & 一般 \\
\hline \multirow{2}{*}{ 好次数 } & 0 & 1 & 0 \\
\cline { 2 - 4 } 较好次数 & 2 & 4 & 4 \\
\cline { 2 - 4 } 一般次数 & 4 & 2 & 4 \\
\cline { 2 - 4 } 差次数 & 2 & 1 & 0 \\
\hline 总分 T & 16 & 21 & 20 \\
\hline
\end{tabular}

表 3 为 A、B、C 三个项目各评价指标的值, 按照信息熵值法的计算步骤得出表 4, 即这三个项目的绩效评价值。从 
总体的评价结果来看, 这三个政府投资项目的总体绩效值都不高, 属于偏低水平。从计算过程中各指标的权重来看, 财务净现值和项目管理有效性是制约政府投资项目绩效值的主要因素。而由表 2 可以看出, 项目管理有效性专家打分 都不高, 说明政府投资项目在项目管理有效性方面仍存在一些困难和不足，这在很大程度上制约了政府投资项目的绩 效水平。同时, 这三个项目的绩效审计评价结果也在一定程度上反映出了目前我国政府投资项目建设和运行的现状。 基于政府投资项目的特殊性，关注重点往往会放在财政资金使用的高效性和成果性，但通常会忽视项目从立项决策到 投产运营整个建设期间的项目管理水平，然而这一点却是决定政府投资项目绩效水平的一个至关重要的因素。因此， 提高政府投资项目绩效水平可将提升整个项目管理水平作为突破口，以获得更好效果。

表 3 A、B、C 三个政府投资项目各绩效评价指标值

\begin{tabular}{c|c|c|c|c|c}
\hline \multirow{2}{*}{ 维度 } & 指标 & 单位 & A 项目 & B 项目 & C 项目 \\
\hline \multirow{4}{*}{ 经济性 } & 审批程序规范率 & $\%$ & 60 & 70 & 75 \\
\cline { 2 - 6 } & 设计浪费率 & $\%$ & 25 & 26 & 23 \\
\cline { 2 - 6 } & 资金到位率 & $\%$ & 70 & 65 & 68 \\
\cline { 2 - 6 } & 建安工程费增减率 & $\%$ & 3 & 2 & 2.5 \\
\cline { 2 - 6 } & 设备购置费增减率 & $\%$ & 1.5 & 1.6 & 1.3 \\
\hline \multirow{5}{*}{ 效率性 } & 财务净现值 & 万元 & 15000 & 13000 & 16000 \\
\cline { 2 - 6 } & 资金闲置率 & $\%$ & 0.8 & 0.6 & 0.7 \\
\cline { 2 - 6 } & 资金支出合法合规率 & $\%$ & 90 & 93 & 87 \\
\cline { 2 - 6 } & 招投标制执行率 & $\%$ & 65 & 68 & 60 \\
\hline \multirow{5}{*}{ 效果性 } & 投资回收期 & 年 & 5 & 4.5 & 6 \\
\cline { 2 - 6 } & 项目管理有效性 & 分值 & 16 & 21 & 20 \\
\cline { 2 - 6 } & 工程质量优良品率 & $\%$ & 50 & 55 & 57 \\
\cline { 2 - 6 } & 建设管理费率 & $\%$ & 0.7 & 0.65 & 0.6 \\
\hline
\end{tabular}

表 4 政府投资项目绩效评价值

\begin{tabular}{cccc}
\hline 项目名称 & A 项目 & B 项目 & C 项目 \\
\hline 绩效值 & 0.3214 & 0.3814 & 0.2972 \\
\hline
\end{tabular}

[参考文献]

[1]周翔,姜文军,沃野.关于人民银行开展绩效审计的思考 [J]. 金融纵横, 2012(10): 59-63.

[2]窦娟. 政府投资建设项目绩效审计评价指标体系的研究 [D]. 兰州: 兰州大学, 2013.

[3] 谭跃进. 定量分析方法 [M]. 北京: 中国人民大学出版社,2002.

[4] 施建刚, 黄耀明. 基于模糊数学的房地产估价实务 $[\mathrm{J}]$. 东南大学学报, 2002(3) : 30-32.

[5]油翠英, 苏振民, 余小颉。建筑企业集团技术中心运行绩效评价一基于信息摘值法的实证研究 [J]. 科技管理研 究, 2013 (21): 51-60.

作者简介: 油翠英 (1987.1-), 女, 汉语, 新疆人, 工程师, 硕士研究生, 主要从事以政府投资为主的建设项目跟踪 审计与结算审计工作，包括土建、市政配套、绿化、交通等方面。 